\title{
Heavy Metals Biosorption in Liquid Solid Fluidized Bed by Immobilized Consortia in Alginate Beads
}

\section{R llamathi ${ }^{1 *}$, GS Nirmala ${ }^{2}$ and L Muruganandam ${ }^{3}$}

${ }^{1}$ Department of Biotechnology, SNIST, Yamnampet, Hyderabad, Andhra Pradesh, India

${ }^{2,3}$ Chemical Engineering Division, School of Mechanical and Building Sciences, Vellore Institute of Technology, Vellore, India

\begin{abstract}
The adsorptive removal chromium, nickel, copper and cadmium by alginate beads containing a mixed consortium of Yeast, Pseudomonas aeruginosa, Bacillus subtilis and Escherichia coli in batch and fluidized bed column reactor was investigated. Under optimized conditions ( $\mathrm{pH} 4.5$; contact time $3 \mathrm{hrs}$; initial metal concentration of $150 \mathrm{mg} / \mathrm{L}$ ) batch experiments showed that the immobilized mixed culture was successfully used for the removal of these metal ions in waste water. Fluidized bed studies were carried out in with an adsorbent dosage of $1 \mathrm{~g} / \mathrm{L}$, a flow rate of $132 \mathrm{LPH}$, a bed height of length of the reactor. Efficiency of biosorption for copper, cadmium, chromium and nickel was found to be $84.62 \%, 67.17 \%, 49.25 \%$ and $61.02 \%$. Desorption of the exhausted beads was found to be successful, however with a reduced biosorption capacity.
\end{abstract}

Keywords: Liquid solid fluidized bed; Immobilization; Heavy metals; Biosorption

\section{Introduction}

One of the most challenging environmental problems is the removal of heavy metals and other toxic contaminants from industrial wastewater of the important metals, Mercury, lead, cadmium, Arsenic and Chromium (VI) are regarded as toxic; whereas, others such as copper, nickel, cobalt and zinc are not as toxic, but their extensive usage and increasing levels in the environment are of serious concerns $[1,2,3]$. Several methods are being used for the removal of heavy metals ions from aqueous wastes (Chemical Precipitation, Ion Exchange, Electrochemical Treatment, Membrane Technologies, adsorption on activated Carbon. etc. [4]. Each of these methods has its own merits and demerits. But the search for new eco-friendly and cost-effective technology for the removal of heavy metals from wastewaters has been directed towards biosorption.

Biosorption using potential metal biosorbents like algae, bacteria, fungi, and yeast can be an effective technique to decrease the concentration of heavy metal ions in solution [5]. Reduction of hexavalent chromium $\mathrm{Cr}$ (VI) to $\mathrm{Cr}$ (III) by bacteria such as Pseudomonas aeruginosa [6], Bacillus sp. [7] and Escherichia Coli [8] is already reported. However, application of free bacterial cells at industrial scale is disadvantageous due to the difficulty of biomass/effluent separation [9] etc., which may be overcome by using immobilized bacterial cells with the advantages of stability, regeneration, solid-liquid separation and minimal clogging in continuous systems [10]. Immobilization of microorganisms in a suitable matrix like polyvinyl alcohol, agar media and sol-gel materials has been proven to be an efficient solution to this problem $[11,12]$.

Adsorption processes are traditionally carried out in fixed beds [13] due to the high concentration of solids and the obtainable uniform residence time. However since the wastewater to be treated often contains solid impurities leading to a plugging of the fixed bed, the liquid must be clear to avoid column blocking. Recently, many experimental studies have been conducted in fluidized beds, which allow treatment of turbid liquids while avoiding the channeling problems [14]. Fluidized beds are common and important reactors in process engineering because of the good mass and heat transfer rate between the fluid and the particles, and between the particles and the side wall of the column. The term fluidization is used to describe the condition of fully suspended particles. Liquids or gases are passed at certain velocity up through a bed of solid particles, at this velocity the pressure drop across the bed counter balances the force of gravity on the particles and further increase in velocity achieve fluidization at a minimum fluidization velocity. Fluidization quality is closely related to the intrinsic properties of particles, e.g. particle density, particle size and size distribution, and also their surface characteristics [15]. From the previous literature related to the biosorption of heavy metal using bacteria, it can be concluded that there is a lack in literature of using immobilized bacterial consortia in liquid solid fluidized bed to study the behavior of biosorbents and its efficiency in heavy metal adsorption. Hence, this work aims to study the adsorption of heavy metals like chromium, nickel, copper and cadmium in liquid solid fluidized bed using immobilized sol-gels as a solid catalyst containing mixed cultures of Yeast, Pseudomonas aeruginosa, Bacillus subtilis and Escherichia coli.

\section{Materials and Methods}

\section{Materials}

Microorganisms: Pseudomonas aeruginosa, Bacillus subtilis, E.coli, Yeast obtained from the laboratory culture collection was maintained in the specific medium and appropriate proportions used for the experiment. Standard sterile techniques were used for inoculation of cultures. Medium used for the microorganism and all the glassware were properly sterilized autoclaved at $15 \mathrm{lb} / \mathrm{in}^{2}$ pressure and $121^{\circ} \mathrm{C}$ for 30 minutes.

*Corresponding author: R Ilamathi, Department of Biotechnology, SNIST, Yamnampet, Hyderabad, Andhra Pradesh, India, Tel: 91-9014339148; Fax : 91-040-27640394; Email: mathigmagnate@gmail.com

Received November 30, 2013; Accepted January 02, 2014; Published January 08, 2014

Citation: Ilamathi R, Nirmala GS, Muruganandam L (2014) Heavy Metals Biosorption in Liquid Solid Fluidized Bed by Immobilized Consortia in Alginate Beads. J Bioprocess Biotech 4: 145 doi: 10.4172/2155-9821.1000145

Copyright: (c) 2014 Ilamathi R, et al. This is an open-access article distributed under the terms of the Creative Commons Attribution License, which permits unrestricted use, distribution, and reproduction in any medium, provided the original author and source are credited. 


\section{Methods}

Preparation of metal solutions: Different metal concentrations were prepared by dissolving of $\mathrm{CuCl}_{2}, \mathrm{CdCl}_{2}, \mathrm{NiSO}_{4}$ and $\mathrm{K}_{2} \mathrm{Cr}_{2} \mathrm{O}_{7}$ salts in double distilled water in equal ratio to have metal concentrations of $50,100,150,200,250$ and $300 \mathrm{mg} / \mathrm{L}$. A stock solution of $1000 \mathrm{mg} / \mathrm{L}$ was prepared all other concentrations are obtained from it. All glassware washed with $0.1 \mathrm{M} \mathrm{HCl}$ before and after each experiment to avoid binding of the metal to it.

Preparation of biosorbent: The culture was transferred and grown on specific media (Bromifield medium-Bacillus subtilis; Cetrimide medium-Pseudomonas aeruginosa; YPD-Yeast; LB medium-E.coli) for subculture. $100 \mathrm{ml}$ of sterilized culture media was transferred to 250 $\mathrm{ml}$ Erlenmeyer flask. The media was allowed to cool and then the $100 \mu \mathrm{l}$ microbial solution was inoculated into the medium in laminar air flow chamber. The inoculated flasks were incubated in an orbital shaker at $250 \mathrm{rpm}$ at $32^{\circ} \mathrm{C}$ for 2 days to obtain the biomass. Mixed cultures were prepared by adding equal amounts of individual cultures. Biomass was harvested from the medium by centrifugation at $9000 \mathrm{rpm}$ for 10 min. The supernatant was discarded and the cells were re-suspended in double distilled water (MilliQ) for washing and again centrifuged as above to make sure that no media remain on the cell surface. This biomass was used for sorption studies.

Immobilization of biosorbent: A $4 \%(\mathrm{w} / \mathrm{v})$ solution of sodium alginate was prepared by continuous stirring in hot $\left(60^{\circ} \mathrm{C}\right)$ distilled water. After cooling, $5 \%(\mathrm{w} / \mathrm{v})$ of bacterial consortia was added and stirred. The mixture was extruded using a burette into $0.5 \mathrm{M} \mathrm{CaCl}_{2 \cdot 2} \mathrm{H}_{2} \mathrm{O}$. The resultant beads were kept in the polymerizing medium for $4 \mathrm{~h}$. The beads were washed in saline and distilled deionized water. The beads were frozen at $20^{\circ} \mathrm{C}$ for $24 \mathrm{~h}$, kept at $4^{\circ} \mathrm{C}$ for $12 \mathrm{~h}$, and thawed at room temperature for further use.

\section{Batch biosorption studies}

Optimization of parameters: Batch studies were done using biomass as a function of various parameters such as $\mathrm{pH}$, time, temperature, initial metal concentration and bed height. Biosorption experiments were conducted at an initial metal concentration of 100 $\mathrm{mg} / \mathrm{L}$ and $100 \mathrm{mg}$ sorbent in $100 \mathrm{ml}$ of metal solution at $30^{\circ} \mathrm{C}$ for 3 hours at $\mathrm{pH}$ varying from 1.0 to 7.0 by adding $0.01 \mathrm{~N} \mathrm{HCl}$. Effect of contact time was studied at an initial metal concentration of $100 \mathrm{mg} / \mathrm{L}$ and $100 \mathrm{mg}$ sorbent in $100 \mathrm{ml}$ solution at $30^{\circ} \mathrm{C}$ and optimized $\mathrm{pH}$. Samples were analyzed for the concentration of metal at regular interval of one hour for 24 hours. The effect of temperature on sorption was determined through batch experiments carried out at 10,20,30, 40 and $50^{\circ} \mathrm{C}$. Sorption studies at optimized conditions were also carried out with initial metal concentrations in the range of $50-300 \mathrm{mg} / \mathrm{L}$ of metal solutions prepared as stated in section 2.2.1. Biosorbent dosage was optimized by using biosorbent amounts of 25, 50, 75, 100, 125 and 150 $\mathrm{mg}$ in $100 \mathrm{ml}$ of $100 \mathrm{mg} / \mathrm{L}$ of metals solutions. The optimization studies were carried out for mixed culture immobilized in alginate beads.

\section{Experimental Protocol for LSFB}

Experimental setup: Figure 1 shows the fabricated LSFB consists of a homogenizing section $14 \mathrm{~cm}$ long for the uniform mixing of the inlet wastewater before it enters the reactor. Above the homogenizing section is the distributor plate of diameter $5 \mathrm{~cm}$, with pores of diameter $1.5 \mathrm{~mm}$ arranged in triangular pitch. Above the distributor plate is an acrylic riser of $88 \mathrm{~cm}$, which functions as the LSFB. There is a solid disengaging section above the riser, from where the liquid effluent is withdrawn. Pressure tapings were made at different heights.
Ball valves are used for the inlet and the bypass. The LSFB requires a $1 / 2$ HP pump for the inlet. A rotameter of range 0-300 LPH was used to vary the flow rate. Immobilized Sodium Alginate beads were selected as the fluidizing particle. The main advantage of using Sodium Alginate is that it doesn't react with water. Also, it has small diameter and low density, and hence, it is easier for fluidization and entrainment. Another advantage is that it fluidizes at low liquid flow rate. Hydrodynamics studies were carried out on the LSFB using Alginate beads as the fluidizing particle to study its behavior and to check its functioning.

Experimental Procedure: The fluidized bed is initially filled with beads up to a $1 / 4^{\text {th }}$ of the total riser volume. Tap water is pumped from the reservoir into the reactor column using a $1 / 2 \mathrm{HP}$ pump. The flow rate of the liquid is measured using a rotameter with a range of 0 to $300 \mathrm{LPH}$. At each flow rate, the bed height is measured and tabulated. The pressure drop across the column is also measured using a digital manometer and tabulated. The void age is calculated at minimum fluidization velocity and at different flow rates. The pressure drop across the bed was found to be the same for different flow rates, thus indicating the proper construction of the LSFB.

Biosorption studies in LSFB: Immobilized biosorbent prepared as per section 2.2.3 was filled in the fluidized bed till $1 / 4^{\text {th }}$ of the riser volume. 30 liters of synthetic heavy metal solution was prepared as described in section 2.2.1. The prepared heavy metal solution $(100 \mathrm{mg} / \mathrm{L})$ was pumped through the column at desired flow rate of $132 \mathrm{LPH}$ which was determined by the hydrodynamic studies in the column. Optimized parameters were used, and the heavy metal concentration was determined using atomic absorption spectrophotometer at $5 \mathrm{~min}$ interval in the start of the experiment and then at 15 min intervals subsequently from the sampling port. The fluidized bed studies were carried out at pH 4.5 at room temperature. The effect of pressure drop and bed height on different flow rate on heavy metal adsorption was studied. Samples were collected at pre-defined time intervals, centrifuged as above and the amount of metal in the supernatant was determined.

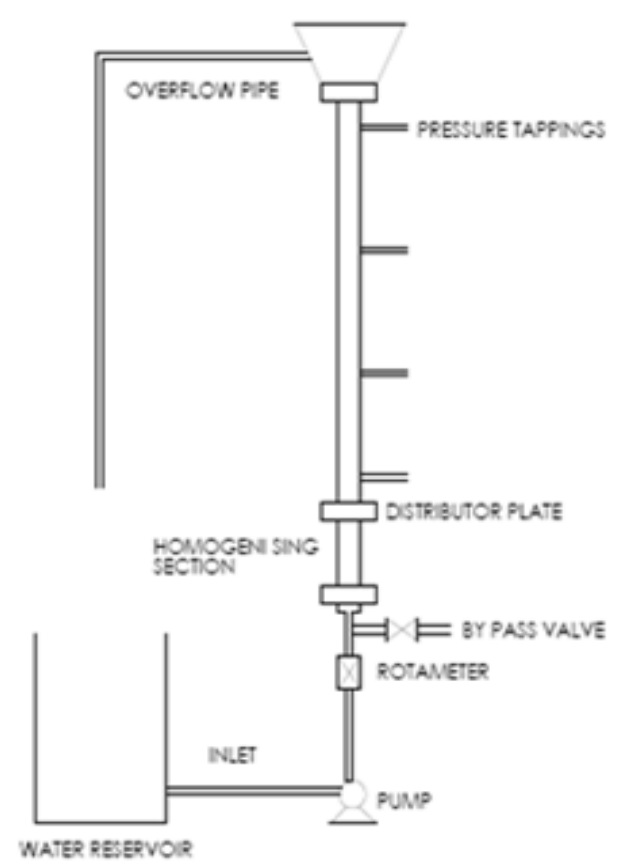

Figure 1: Schematic diagram of the experimental setup. 
Determination of metal concentration in the supernatant: The heavy metal concentration was determined by the use of atomic absorption spectrophotometer, Perkin Elmer Analyst 300. Determination of copper, chromium, cadmium and nickel was done by using its specific lamp for each metal and at a specific wavelength.

Data evaluation: The amount of metal bound by the biosorbents was calculated as follows:

$$
Q=v(C i-C f) / m
$$

Where $\mathrm{Q}$ is the metal uptake (mg metal per g biosorbent), $v$ the liquid sample volume $(\mathrm{ml}), C_{i}$ the initial concentration of the metal in the solution $(\mathrm{mg} / \mathrm{L}), C_{f}$ the final (equilibrium) concentration of the metal in the solution $(\mathrm{mg} / \mathrm{L})$ and $\mathrm{m}$ the amount of the added immobilized biosorbent on the dry basis $(\mathrm{mg})$.

Desorption studies: The exhausted Alginate beads containing immobilized microorganisms after heavy metal biosorption were removed from the LSFB. The beads were then treated with Nitric Acid, and allowed to stay for an hour and loaded back into the LSFB. $10 \mathrm{ml}$ of samples were withdrawn every half hour. The samples were then analyzed in the Atomic Absorption Spectrophotometer to determine the heavy metal concentration.

Sample analysis: Metal concentration at initial and at regular intervals was examined using atomic absorption spectrophotometer $10 \mathrm{ml}$ of the samples were taken out for every 5 minutes in the first hour and continued by every $15 \mathrm{~min}$ in the subsequent hour. The metal concentrations were determined and the results are tabulated.

\section{Results}

\section{Batch sorption studies}

\section{Effect of batch sorption parameters}

Effect of pH: The experimental results of chromium,cadmium,nickel and copper using mixed cultures of Yeast, Pseudomonas aeruginosa, Bacillus subtilis and Escherichia coli at varying $\mathrm{pH}$ was shown in the Figure 2(A). Effect of $\mathrm{pH}$ on biosorption has been studied over a range of 1 to 7 . The highest removal of cadmium and copper was found at $\mathrm{pH} 4$, while at $\mathrm{pH} 3$ and 5 the highest removal of chromium and nickel obtained respectively. At $\mathrm{pH}<3$, lowest biosorption was recorded and the experiments beyond $\mathrm{pH} 5$ were hindered due to precipitation of metals during the biosorption process.

Effect of contact time: Before the starting of the batch experiments, it was very important to know the required time to reach equilibrium biosorption. In other words, for all batch experiments, the contact time should be sufficient to ensure reaching an equilibrium concentration. Figure 2(B) shows the results of biosorption removal of heavy metals concentration versus contact time for the four metal solutions. It can be seen that a 3 hour contact time is sufficient to reach equilibrium for all four heavy metals.

Effect of temperature: Biosorption studies of Metals solutions using immobilized mixed cultures were carried out at different temperatures ranging from $10^{\circ} \mathrm{C}$ to $50^{\circ} \mathrm{C}$. The effect of temperature on metal sorption was presented in Figure 2(C). The percentage of metal sorption was increased from $10^{\circ} \mathrm{C}$ to $30^{\circ} \mathrm{C}$ and then showed decrease in sorption percentage with increase in temperature. Figure 3.4 shows a maximum percent of sorption around $90 \%$ achieved at $30^{\circ} \mathrm{C}$ at fixed $\mathrm{pH}$ 4.5 and biomass concentrations $2.0 \mathrm{mg} / \mathrm{ml}$. This decrease in biosorption efficiency at temperatures $40-50^{\circ} \mathrm{C}$ may be attributed to: an increase in the relative desorption of the heavy metals from the solid phase to the liquid phase, deactivation of the biosorbent surface, destruction of active sites on the biosorbent surface due to bond disruption, or due to the weakness of the sorbent active site binding forces and the sorbate species and also between the adjacent molecules of the sorbed phase. From Figure 3 it was concluded that experiments can be carried out at room temperature.

Effect of initial metal concentration: Figure 2(D) shows the variation of percentage sorption of immobilized microbial culture at different initial metal concentrations. The results indicated that the percentage biosorption of metals was not altered greatly from concentrations between $50-150 \mathrm{mg} / \mathrm{L}$ whereas still increasing in the initial metal concentration beyond $150 \mathrm{mg} / \mathrm{L}$ shows a decrease in the sorption capacity, this may be due to the sorbent dosage depicted in Figure 2(E) which was found to be $1 \mathrm{~g} / \mathrm{L}$ of immobilized biosorbent containing enough biosorption surfaces and sites for this concentration.

\section{LSFB studies for biosorption}

Effect of pressure drop and flow rate: From Figure 3(A), it is evident that the pressure drop across the LSFB increases continuously till the flow rate of the liquid attains that of the minimum fluidization velocity, which is the velocity required to fluidize the particles, in this case, the Alginate beads. On further increase of the flow rate of the liquid beyond minimum fluidization velocity (43 LPH), the pressure drop across the LSFB is found to remain nearly constant, hence obtaining a straight line in the latter part of the graph. This signifies that once the fluidization starts, the pressure drop across the LSFB remains the same for different flow rate.

Effect of bed height and flow rate: Figure 3(B) shows that the bed height of the constructed Liquid Solid Fluidized Bed (LSFB) remains constant till the flow rate reaches the minimum fluidization velocity, which is $43 \mathrm{LPH}$ for the above mentioned bed. Since the beads are supposed to fill $25 \%$ of the entire volume of the reactor, the static bed height is $22 \mathrm{~cm}$. Once the flow rate of the liquid exceeds the minimum fluidization velocity, the fluidization of the beads starts and the bed expands. The bed height was found to increase more or less linearly with the liquid flow rate. This indicates the proper construction of the LSFB.

The optimum flow rate was determined as $132 \mathrm{LPH}$ since it was found that at this flow rate, the bed height is the length of the reactor. In other words, at a liquid flow rate of $132 \mathrm{LPH}$, the beads filled the entire length of the column, without any overflow.

LSFB biosorption studies under optimized conditions: Biosorption studies in LSFB were conducted, which was packed with the known quantity of immobilized alginate beads. The synthetic metals solution was pumped at desired flow rate. Optimized parameters were used and the metal concentrations were determined by atomic absorption spectrophotometer at an interval of $15 \mathrm{~min}$ from the sampling port. Figure 3(D) shows the plot of metals concentration in the LSFB against the residence time in the fluidized bed. The maximum amount of copper was adsorbed in the first 170 minutes. Nickel, Chromium and cadmium were adsorbed at $70 \mathrm{~min}$. The maximum efficiency of biosorption of Cadmium in the LSFB was found to be 67.17\%. Biosorption of Chromium using in the LSFB was also found to increase up to 90 minutes, after which the biosorbed metal leached back into the solution. The maximum biosorption efficiency for uptake of Chromium (VI) metal was calculated to be $49.25 \%$. Biosorption of copper in the LSFB were found to be high than other metals this may be due to the high suitability of optimized parameters and enough surfaces 
Citation: Ilamathi R, Nirmala GS, Muruganandam L (201) Heavy Metals Biosorption in Liquid Solid Fluidized Bed by Immobilized Consortia in Alginate Beads. J Bioprocess Biotech 4: 145 doi: 10.4172/2155-9821.1000145

(A)

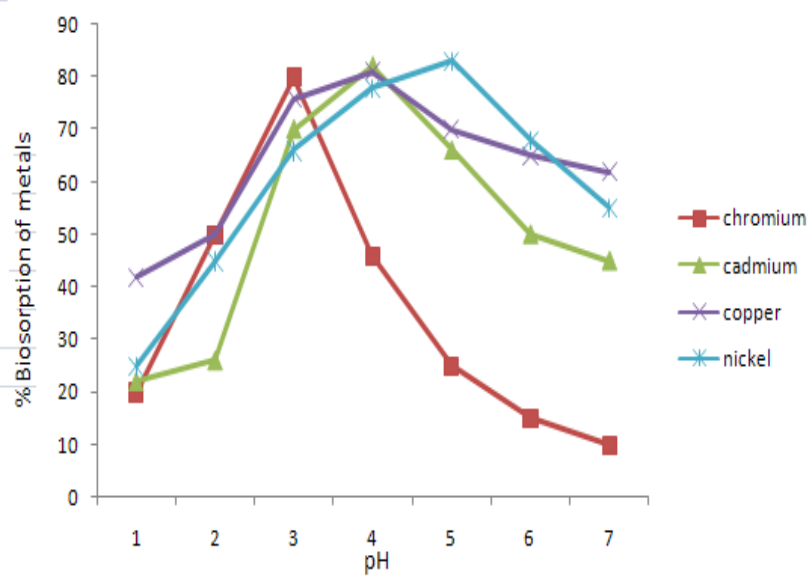

(C)

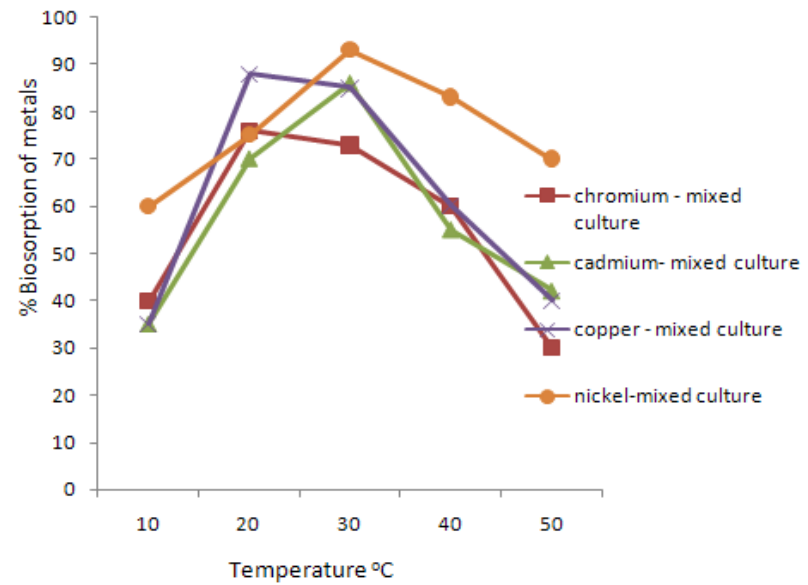

(B)

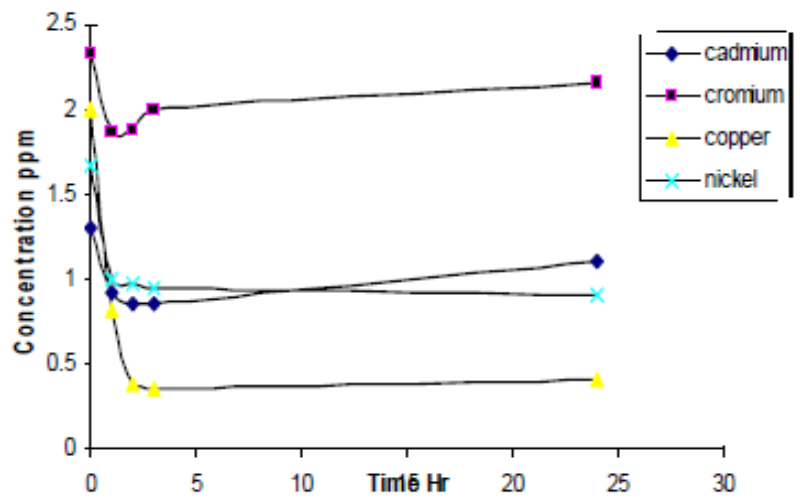

(D)

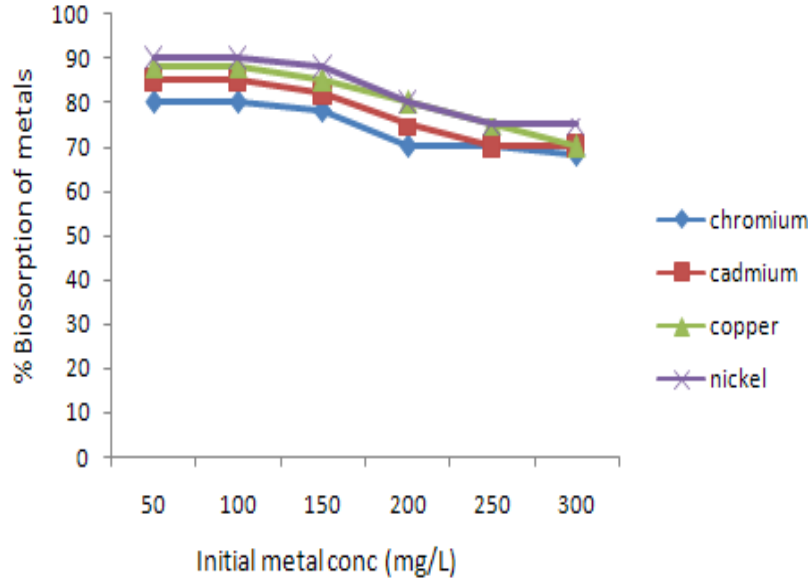

(D)

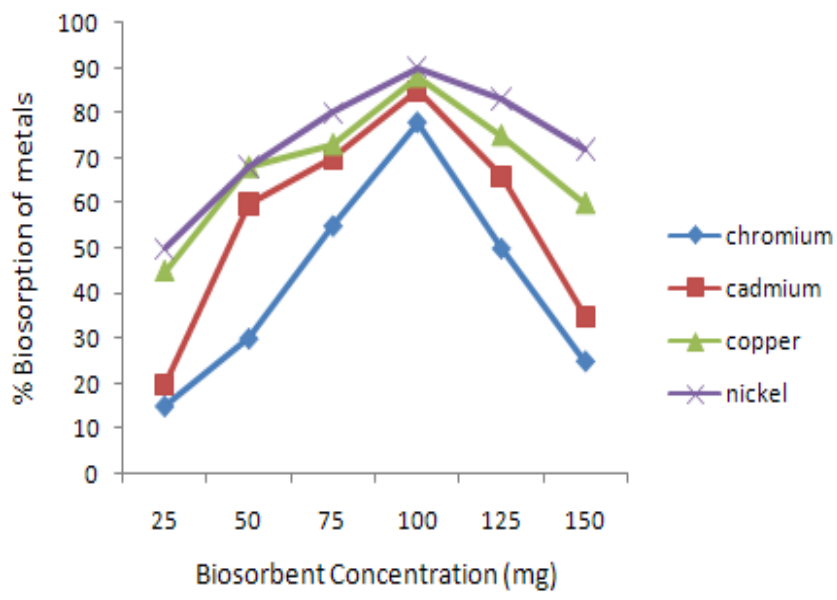

Figure 2: (A) Effect of pH. (B) Contact time (C) Temperature (D) Initial Metal Concentration (E) Biosorbent Concentration of the bacterial consortium immobilized in alginate beads. 
Citation: Ilamathi R, Nirmala GS, Muruganandam L (2014) Heavy Metals Biosorption in Liquid Solid Fluidized Bed by Immobilized Consortia in Alginate Beads. J Bioprocess Biotech 4: 145 doi: 10.4172/2155-9821.1000145

(A)

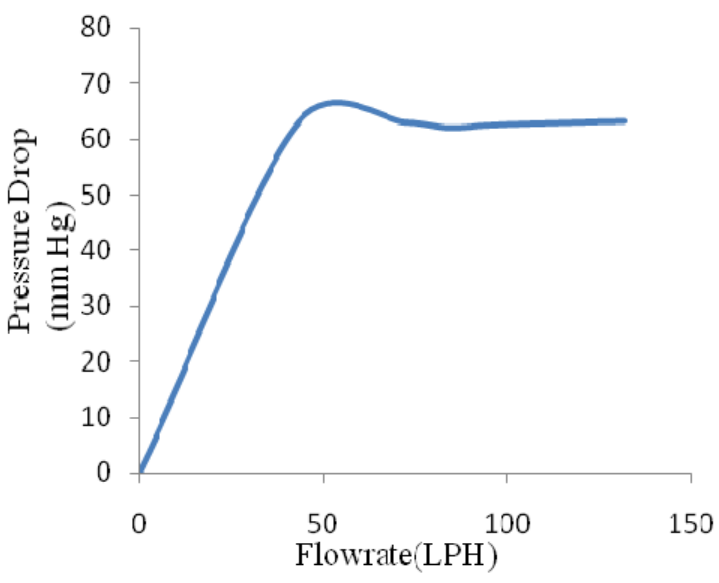

(C)

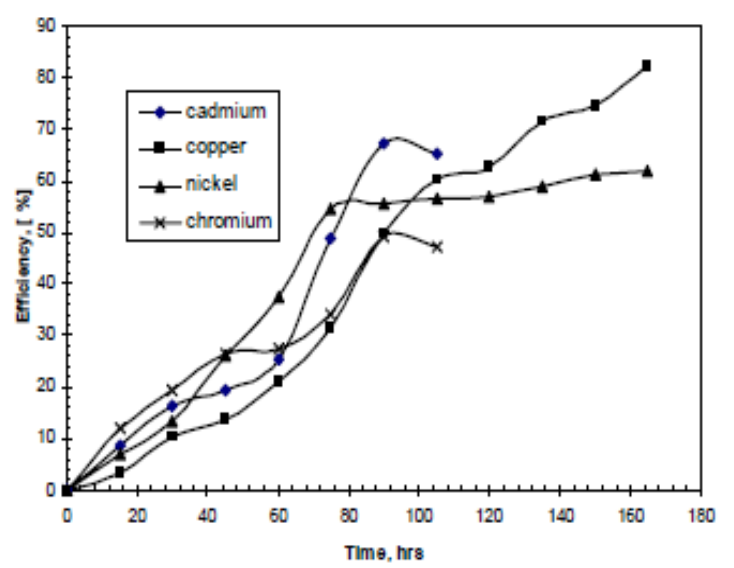

(B)

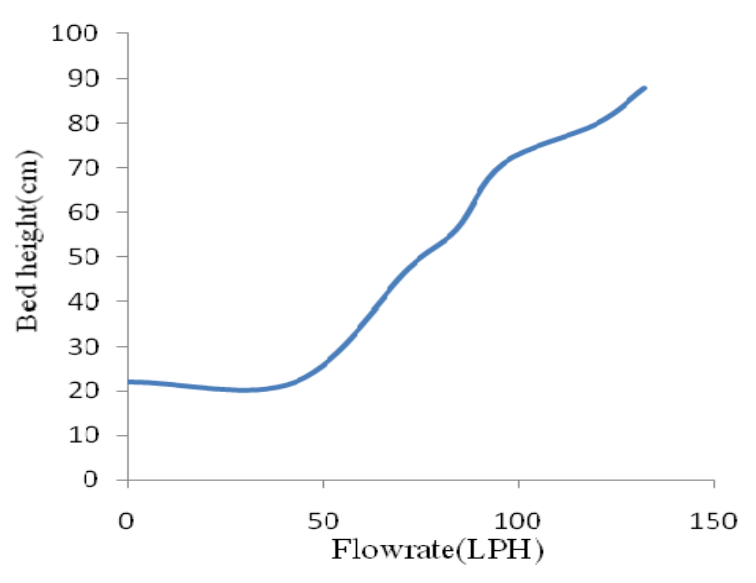

(D)

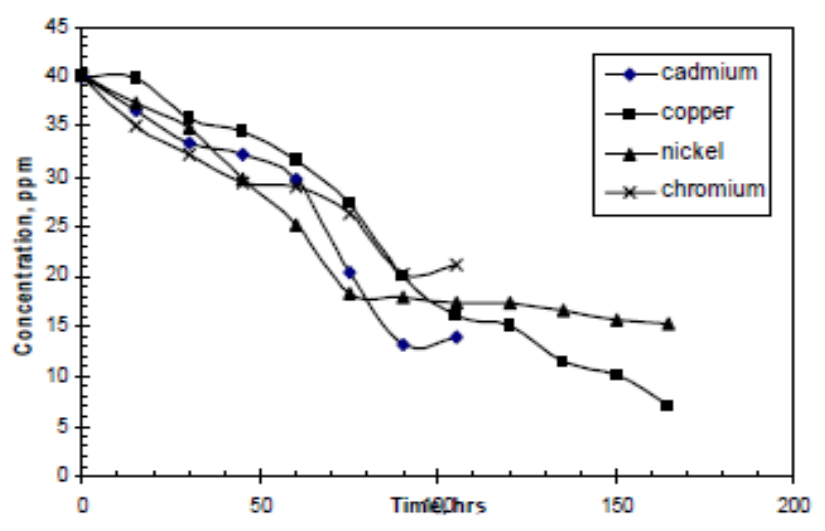

(E)

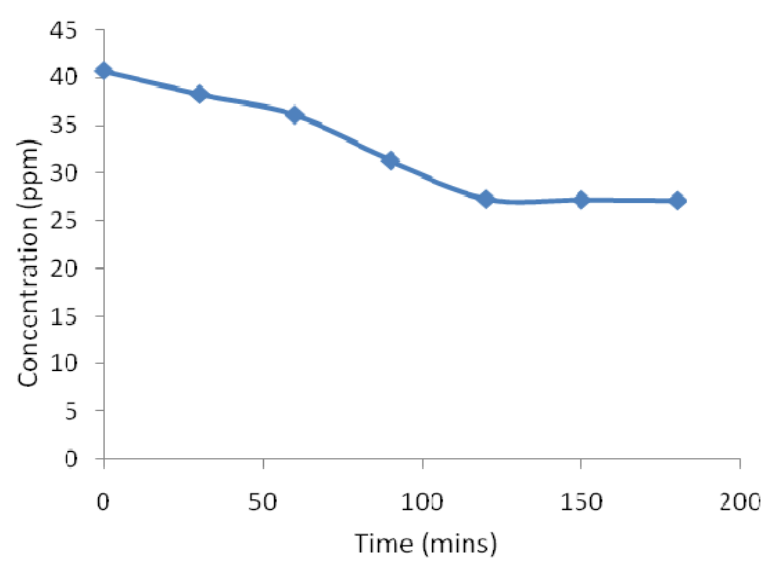

Figure 3: (A) Effect of Pressure drop and flow rate (B) Bed height on flow rate (C) Efficiency of Fluidized bed sorption studies (D) Removal of metal concentration in LSFB on time (E) Desorption studies on removal of copper. 
Citation: Ilamathi R, Nirmala GS, Muruganandam L (2014) Heavy Metals Biosorption in Liquid Solid Fluidized Bed by Immobilized Consortia in Alginate Beads. J Bioprocess Biotech 4: 145 doi: 10.4172/2155-9821.1000145

Page 6 of 6

and sites for this concentration. The optimum time for the biosorption was determined to be around nearly 3 hours, after which the biosorption efficiency remains more or less constant which is same as that of the batch studies. Similar to the batch studies performed, the concentration of Copper in the solution was found to continuously decrease in the first 3 hours. Figure 3(C) gives the maximum biosorption efficiency of metals in which the copper biosorption efficiency in the LSFB was determined to be high as $84.62 \%$. Biosorption efficiency of the other metals may increase by optimizing the biomass concentration of each microorganism with respect to the metals solution before immobilizing in alginate beads.

Desorption and column regeneration: The desorption of exhausted Alginate beads containing mixed culture using $0.1 \mathrm{~N}$ Nitric Acid. Figure 3(E) shows the concentration of was found to decrease from $40 \mathrm{ppm}$ to $27.12 \mathrm{ppm}$ for copper. The efficiency was found to decrease from $82.4 \%$ to $33.46 \%$. Reusability of biosorbent was studied by three cycles of alternating sorption/desorption experiments with the supplement of $100 \mathrm{mg} / \mathrm{L}$ of metals solution at the beginning of each cycle. The sorption capacities for each cycle were shown to be decreasing by $5 \%$.

\section{Conclusion}

The present study evaluated the removal of copper, chromium, nickel and cadmium from synthetic metals solutions using immobilized consortium of Yeast, Pseudomonas aeruginosa, Bacillus subtilis and Escherichia coli in alginate beads in fluidized bed reactor. Batch experiments showed that the mixed culture immobilized in alginate beads can be successfully used for the removal of these metal ions. LSFB studies showed that the removal of copper and nickel was high compared to chromium and cadmium. This concluded that biosorption was found to depend significantly on $\mathrm{pH}$ of the solution. Optimum flow rate 132 LPH obtained from batch studies results in good contact time between the adsorbent and adsorbate in LSFB also. It can thus be concluded from this project work that biosorption of heavy metals in an LSFB is not only a cost effective method, but also a highly efficient alternative to chemical and physical treatments employed for the removal of heavy metal pollutants from contaminated water. Further work will be carried out in developing a model with higher fluidization velocity with different particle size and with different biomass concentration.

\section{References}

1. Brown B, Absanullah M (1971) Effects of Heavy Metals on Mortality and Growth. Mar Pollut Bull 2: 182-187.

2. Moore JW (1991) Inorganic Contaminants of Surface Water. Research and Monitoring Priorities.

3. Volesky B, Holan ZR (1995) Biosorption of heavy metals. Biotechnol Prog 11 235-250.

4. Matheickal JT, Yu Q (1999) Biosorption of lead (II) and Copper (II) from aqueous solution by pretreated biomass of Australian marine algae. Bioresour Technol 69: 223-229.

5. Volesky B (1986) Biosorbent materials. Biotechnol Bioeng Symp 16: 12-126.

6. Song HX, Liu YG, Xu WH, Zeng GM, Aibibu N, et. al, (2009) Simultaneous $\mathrm{Cr}(\mathrm{VI})$ reduction and phenol degradation in pure cultures of Pseudomonas aeruginosa CCTCC AB91095. Bioresour Technol 100: 5079-5084.

7. Wang YT, Xiao C (1995) Factors Affecting Hexavalent Chromium Reduction in Pure Cultures of Bacteria. Water Res 24: 2467-247.

8. Liu GF, Yang H, Wang J, Jin RF, Zhou JT, et. al., (2010) Enhanced Chromate Reduction by Resting Escherichia Coli Cells in the Presence of Quinone Redox Mediators. Bioresour Technol 101: 8127-8131.

9. White C, Wilkinson SC, Gadd GM (1995) The Role of Microorganisms in Biosorption of Toxic Metals and Radionuclides. Int Biodeterior Biodegradation 35: $17-40$.

10. Viera M, Curutchet G, Donati E (2003) A Combined Bacterial Process For The Reduction And Immobilization of Chromium. Int Biodeterior Biodegrad 52: 31-34.

11. Saraj MA, Abdel-Latif MS, El-Nahal I, Baraka R (1999) Bioaccumulation of Some Hazardous Metals by Sol-Gel Entrapped Microorganisms. J Non-Cryst Solids 248: 137-140

12. Xu J, Song XC, Zhang Q, Pana H, Liang Y, et. al., (2011) Characterization of Metal Removal of Immobilized Bacillus Strain CR-7 Biomass from Aqueous Solutions. J Hazard Mater 187: 450-458.

13. McDougall GJ, Fleming CA (1987) Extraction of precious metals on activated carbon, in lon Exchange and Sorption Processes in Hydrometallurgy, Ed. by Streat, M. and Naden, D., Critical Reports on Applied Chemistry. 19: 56-126.

14. Fu Y, Liu D (2007) Novel Experimental Phenomena of Fine-Particle Fluidized Bed. Exp Therm Fluid Sci 32: 341-344

15. Richardson JF, Harker JH, Bachurst JR (2002) Coulson and Richardson's Chemical Engineering, 5th Edn. Particle Technology and Separation Processes, Butterworth-Heinemann. 